\title{
In-depth profiles of the expectations of undergraduate students commencing university: a $Q$ methodological analysis
}

\author{
Kieran Balloo
}

Department of Psychology, University of Roehampton, London, United Kingdom

Correspondence concerning this article should be addressed to Kieran Balloo,

Department of Psychology, University of Roehampton, London, SW15 4JD,

kieran.balloo@ roehampton.ac.uk, +44 (0) 2083923537.

This is an Accepted Manuscript of an article published by Taylor \& Francis in Studies in Higher Education on 08/05/2017, available online:

http://www.tandfonline.com/doi/full/10.1080/03075079.2017.1320373 
In-depth profiles of the expectations of undergraduate students commencing university:

a Q methodological analysis

Research shows that undergraduate students have many expectations of their university as they commence studying. The current study utilised Q methodology to gain an in-depth understanding of these expectations by examining shared viewpoints between groups of students. First-year undergraduate psychology students ranked statements in their induction week on expectations of university regarding teaching and assessment approaches, lecturer behaviour, organisational and resources support and issues relating to student autonomy. Factor analysis of these ranks revealed three profiles of expectations that were labelled and interpreted holistically in qualitative detail: Expecting to put in the hard work and be supported by tutors, Expecting a different experience to high school and Expecting to strike a balance between university and everyday life. These profiles demonstrate that students' expectations should not be discussed in homogeneous terms. Recommendations are made for educators in terms of understanding discrepancies between expectations and the service which will be provided.

Keywords: expectations of university, transition, feedback, teaching quality, Q methodology

\section{Introduction}

When students make their choice to go to university, they are likely to have certain expectations of their chosen institution (Briggs 2006). Often, these expectations do not match up with the realities of university study (McInnis, James, and Hartley 2000), which could affect students' experiences while undertaking their degrees (Nadelson et al. 2013). While in the 1970s and 1980s higher education was seen as the most important element in the lives of students, Levine (1993) noted a shift in the early 1990s towards universities becoming commodities like banks and supermarkets that students merely use as a means to an end. Therefore, as teachers in higher education are 
increasingly being perceived as service providers, it has been argued that they should be aware of what their customers (i.e. students) expect from their service in order to be able to provide a satisfying experience (Sander et al. 2000). There are many types of expectations that students have about their education, including: teaching and assessment approaches (Sander et al. 2000; Surgenor 2013), lecturer behaviour (Pithers and Holland 2006; Voss, Gruber, and Szmigin 2007), organisational and resources support (Balloo, Pauli, and Worrell 2015) and issues relating to student autonomy, such as time spent studying, attendance, work-life balance, access to teaching staff, and feedback (Brinkworth et al. 2009; Kuh 2007).

Pithers and Holland (2006) surveyed students on their specific expectations of lecturers. It was most important to students that lecturers be experts in the subject matter on which they teach. Other important expectations of lecturers included: effective communication, enthusiasm in their teaching, grading of assessments according to set criteria, providing clear feedback within an appropriate timeframe and an interest in individual students, such as being friendly and approachable. Voss, Gruber, and Szmigin (2007) also found that students emphasised the importance of the lecturer in their university experience. They replicated many of Pithers and Holland's findings, observing that students want their lecturers to be experts with good teaching skills, while also being enthusiastic, good at explaining things and approachable. Sander et al. (2000) established that having 'teaching skills' was seen as the most important teaching quality and that coursework was preferred over exams.

Surgenor (2013) investigated expectations of assessment and found that the majority of students preferred assessments to be evenly spaced throughout the year, rather than all being due in at one or two time points. Students showed a preference for a wide range of assessment approaches, with the most anticipated assessments being 
class tests, and the least expected being oral presentations. Surgenor also discovered that, predominantly, students felt they should receive feedback on all work they submitted and that it was important to them to receive a grade. Similarly, Brinkworth et al. (2009) noted that feedback was deemed to be very important to students and should be received promptly on all work, including draft work. On the other hand, Balloo, Pauli, and Worrell (2015) found that it was most important to students that they receive feedback helping them clarify difficulties, while the prompt return of feedback was significantly less important to them. Balloo, Pauli, and Worrell also established that students had expectations about the support and resources provided by their institution, with clear coursework submission arrangements being most important to them and the timing of teaching sessions being the least important.

Despite these high expectations of what their university should provide them with, students may also have views about what is expected of them and how much commitment they should make to their studies (Crisp et al. 2009). Kuh (2007) claimed that many high school students do not enrol at university with their eyes fully open about what this will entail. He noted that some students expect to work just hard enough to get by, to only need to study for less than 15 hours per week (but to be able to socialise for longer than this), and to have little contact with tutors outside of class time. This latter expectation runs contrary to Brinkworth et al.'s (2009) finding that students feel they should have access to tutors when needed. Therefore, while some students may have high expectations of their university, and the learning experience that the teaching staff should provide, these expectations may not be reciprocated by educators. Furthermore, McInnis, James, and Hartley (2000) found that after one semester, students reported the realisation that there was a significantly higher amount of time needed and work to be done than they expected when they commenced studying. 
Evidence shows that students' expectations about their university education can diverge from the learning experience that university educators intend to provide (Brinkworth et al. 2009). If students' expectations do not match those of the university's teaching staff, it seems likely that their experience will be impacted on negatively. Expectations may factor into students' performance, attendance, drop out risk and their satisfaction with university (Lobo and Gurney 2014). In the United Kingdom (UK), one of the metrics that affects university league tables is student satisfaction, as measured by the National Student Survey (NSS) (Richardson, Slater, and Wilson 2007), which is a census given to final-year undergraduate students (The National Survey 2016). Thus, student satisfaction should not be ignored, and potential ways of improving satisfaction could involve bringing students' experiences more inline with their expectations, or by providing students with more accurate conceptions of what to expect from the outset of their degree.

While there is a body of literature that has already investigated student expectations, currently no attempt appears to have been made to gain an in-depth understanding of these expectations. Many expectations differ in importance between students in the various studies discussed above. Thus, it is unhelpful to discuss particular expectations as something that students hold in unanimity. Balloo, Pauli, and Worrell (2015) discovered that students' expectations differ based on their personal circumstances. For example, it was more important to under-21s than mature students that teaching staff make their subject interesting. While this research reveals that expectations are not merely homogeneous views expressed by students as a whole, knowledge in this area could be extended by attempting to build profiles of shared expectations among students. Balloo, Pauli, and Worrell also recommended that future research in this area should make use of a qualitative approach to gain an in-depth 
understanding of expectations. Nadelson et al. (2013) further proposed that an investigation of commonalities in expectations of groups of first-year students is a useful direction for future research, since it avoids 'blanket statements' being made about these students' expectations. The aim of the current study was to explore undergraduate student expectations of university in more depth than has been undertaken previously and determine whether there are shared viewpoints of expectations between students. The following research question aimed to be addressed: What shared viewpoints of expectations of university exist among newly commencing undergraduate students?

\section{Method}

\section{Design}

The current study employed an approach called Q methodology, which is used to group together shared subjective viewpoints (Brown 1980). Q methodology begins with participants completing a Q sort wherein they are provided with cards containing various attitudes, feelings, beliefs, etc. towards a specific topic (in the current study that topic was student expectations of university). These cards must then be sorted and ranked by participants across a standardised ranking distribution. The rankings given to each card are then submitted to a by-participant factor analysis which results in factors (or profiles) being produced that are then described in qualitative detail to represent shared viewpoints held by groups of participants (Watts and Stenner 2012). The qualitative analysis is explicated by examining open-ended comments that participants convey while completing the Q sort.

In the current study, the statements on the cards were formed by reviewing the literature on student expectations of university, as discussed above. Based on this 
review, students' expectations that were considered in the current study included teaching approaches, assessment methods, lecturer behaviour, organisational and resources support, time spent studying, attendance, work-life balance, access to teaching staff and assignment feedback. Expectations about these aspects of students' education were then written up in the form of statements reflecting subjective views thought to include all perspectives on the subject. A sample of 41 statements were then selected for use on the cards in the current study (see Table 3, column 2 for a list of these statements). The idea behind Q methodology is to be able to gain a range of views about the topic, so each statement was written in a way to attract a range of levels of endorsement and not be seen as simply correct or incorrect.

\section{Participants}

All first-year psychology students from a London-based post-1992 university ${ }^{1}$ were contacted and invited to participate in the study during their induction week, as this was prior to them beginning any university-related academic activities. An opportunity sample of 28 participants were recruited $\left(M_{\text {age }}=20.04\right.$ years, $S D_{\text {age }}=4.33$ years, age range: $17-41$ years). The sample size was limited to the number of participants who had participated by the end of induction week, so that any expectations of university would not be influenced by actual experiences once studying had commenced. Since Q methodology is primarily a qualitative approach focused on identifying a range of perspectives rather than statistical generalisation of every viewpoint that exists, the

\footnotetext{
${ }^{1}$ Post-1992 universities are institutions in the UK that have been awarded university status under the Further and Higher Education Act 1992.
} 
sample size was deemed to be of a sufficient level to achieve this. Table 1 displays the breakdown of the participants' demographics and personal circumstances.

[Table 1 near here]

\section{Materials}

A demographic questionnaire was developed that covered various aspects about participants' backgrounds and personal circumstances, including age, gender, ethnicity, work/caring responsibilities, language, fee status and application route. To present the Q sort to participants, the online Q sorting software FlashQ (Hackert 2007) was utilised. Flash Q provided participants with a Q sorting grid, which had blank spaces onto which virtual cards with statements were dragged. The spaces in the grid were ranked from -4 (most unimportant to me) to +4 (most important to me), with more spaces in the middle of the grid and fewer spaces at the end of the grid. Figure 1 displays this Q sorting grid.

[Figure 1 near here]

\section{Procedure}

Participants who agreed to participate were sent a link to complete the study remotely. After completing the online informed consent form and demographic questionnaire, participants were presented with each of the statements on virtual cards one-by-one in a randomised order and initially instructed to sort the cards into three groups: a group for cards that were important to them, a group for cards that were unimportant to them and a group for cards that were neither important nor unimportant to them. On the next screen, participants were presented with the three groups of cards again, along with the Q sorting grid displayed in Figure 1. Starting with the 'unimportant to me' group, participants were asked to place the cards that were most unimportant to them in the far left column (underneath the -4) and continue placing cards, working towards the middle 
of the Q sorting grid until the group was empty. Participants then moved onto the 'important to me' group and completed the same process with the right side of the grid (underneath the +4 ). Finally, cards from the 'neutral' group were placed in the remaining spaces on the grid. Once all cards were placed on the grid, participants were asked to provide open-ended comments explaining why they placed the particular cards onto the -4 and +4 columns of the grid (i.e. the cards most unimportant and important to them). Participants took 20-30 minutes to complete the entire procedure.

\section{Results}

\section{Statistical Analysis}

In order to form groups of shared viewpoints, the first stage of Q methodology is to perform a by-participants factor analysis on the rankings from the Q sorts (Stainton Rogers 1995). This involved intercorrelating all Q sorts in a 28 x 28 matrix. Schmolck's (2002) specialist Q sort analysis software, PQMethod 2.33, was used to perform a centroid factor analysis with Varimax rotation. Based on the number of participants in the current study, Watts and Stenner (2012) recommend extracting five factors as a starting point and retaining factors with at least two Q sorts loading on them. Solutions accounting for at least $40 \%$ of the study variance and factors with Eigenvalues greater than one are deemed to be acceptable (Watts and Stenner 2005). These criteria were applied and a three factor solution was decided on, which accounted for 26 of the 28 Q sorts and explained $41 \%$ of the study variance. In order to describe the factors in qualitative detail, Q sorts that have loaded on a particular factor (called factor exemplars) are used to form an averaged viewpoint. Of the $28 \mathrm{Q}$ sorts entered into the factor analysis, 26 of the sorts loaded on one of the three factors (in order for a Q sort to be considered a factor exemplar, it must significantly load on a factor and the 
square of the factor loading needs to be greater than half of its communality). Table 2 displays the factor loadings for each Q sort.

[Table 2 near here]

Based on the factor loadings, PQMethod produces composite $\mathrm{Q}$ sorts for each factor that are averages of all of the factor exemplars' Q sorts, called factor arrays. Therefore, there were three factor arrays in the current study representing averages (or composites) of all the exemplars' viewpoints (i.e. shared viewpoints). Table 3 displays the rankings for each statement in each factor array.

[Table 3 near here]

\section{Factor Interpretation}

For the second stage of Q methodology, the factor arrays are interpreted holistically in qualitative detail. Below are qualitative descriptions for each factor array. As part of these descriptions, the interpretations are backed up by the ranking positions of each statement in each array. To demonstrate this, the descriptions include the number statement backing up the interpretation being expressed, along with the ranking of that statement in that factor array (for example, $8:+3$ indicates that statement number 8 was ranked +3 , representing an expectation of importance in that viewpoint). Open-ended comments from participants who loaded on these factors are also provided in quotation marks to further illustrate the narrative being expressed in each viewpoint.

Factor A: Expecting to put in the hard work and be supported by tutors

Demographic summary for factor A. Factor A explained $17 \%$ of the study variance. It had $11 \mathrm{Q}$ sorts loading on it, and these exemplars consisted of 1 male and 10 females, with ages ranging from 18 to $21(M=19.00, S D=1.91)$ years (one mature student). 
Eight exemplars planned to work during term-time, nine had English as a first language, and one was an international student.

Interpretation for factor $A$. The $\mathrm{Q}$ sorts exemplifying factor A represent the expectation to work hard while at university. The view being expressed is that students should be at university to study only, not socialise (23: -4$)$, or do paid work (12: -3$)$. The scheduling of teaching sessions or getting to work with other students is not important for this reason $(7:-4 ; 27:-2 ; 21:-3)$ : 'There [are] always weekends to socialise; we're now paying $£ 9000$ so you have to get your priorities straight' (sort 15). There is no expectation of an 'easy ride', so there is the desire to experience a range of teaching approaches and assessment activities $(32:+1 ; 37:+2 ; 16:-1)$ that are spaced out across the year $(9:+1)$. There is an aspiration for high achievement, so support is expected with areas considered difficult, such as academic writing and maths/statistics $(8:+1 ; 38$ : +3): 'Most students can have difficulties in maths and statistics as it can be hard ... [this support] is giving them guidance and a missing piece of a puzzle or a clue. Again this does NOT mean giving out the answer' (sort 21). However, no shortcuts are being sought by using this support. It is not felt that students should only be taught material needed to pass assignments $(2:-3)$ as there is a yearning to learn as much as possible: 'I would love to know more than just what needs to be taught to pass to widen my knowledge about the subject for wider future job purposes' (sort 13).

As part of this commitment to working hard, a great deal is expected from teaching staff. Feedback is anticipated on all submitted work and drafts $(15:+4 ; 3:+2)$, so there is a familiarity with what to do to improve $(33:+3)$ - 'I feel that all the work which I will be submitting throughout my time on the course should be given feedback. As this will reassure [me] that I am doing well and will also direct me to making improvements, getting better or making changes in the way I approach the assignment 
in the future.' (sort 17) - even if this feedback is critical $(30:+3)$ : 'I would like to be told clearly where I'm going wrong and not have my feedback sugar-coated. Having my work criticised shows me my faults and therefore I know where I need to improve to be the best I can' (sort 20). Therefore, it is envisaged that tutors would highlight exactly what is required to pass assignments and the necessary reading to do this (36: +4 ; 40: +3 ): 'In order for students to receive a good or a high grade on an assignment, the tutors should guide and support students in aiming higher for an actual pass mark ... This does NOT mean giving out the answer; it is giving them a clue to the puzzle they need.' (sort 21). Assignments are expected to be marked promptly $(18:+2)$, with all work being graded $(24:+2)$ and it is felt that tutors should provide opportunities for questions or classroom discussion $(20:+1)$ : 'This is important as I believe we learn more through interaction' (sort 22). It is not necessarily anticipated that tutors would make themselves available outside of class or on an individual basis $(13:-1 ; 35: 0 ; 26$ : $0)$, and neither dependence nor independence on the tutor is foreseen $(5: 0 ; 6: 0 ; 14: 0$; 39: 0); however, the neutral position on this suggests that a collaborative and supportive relationship between the student and tutor is still being sought.

Factor B: Expecting a different experience to high school

Demographic summary for factor B. Factor B explained $16 \%$ of the study variance. It had nine Q sorts loading on it, and these exemplars were all female with ages ranging from 18 to $41(M=21.56, S D=7.37)$ years (two mature students). Four exemplars planned to work during term-time, one was a carer, six had English as a first language, and two were international students. 
Interpretation for factor $B$. The account being articulated in factor $\mathrm{B}$ focuses on the experience of being at university. A different experience to high school/college is strongly being sought (4: -4): '...I hope studying Psychology at uni[versity] is a lot better and [more] in-depth than how it was studied at sixth form. Also, I hope that there are a range of activities and experiments instead of only textbook work' (sort 10). There is no interest in simply being told what to do to pass or exactly what reading is needed (36: $-1 ; 40:-2)$ : '...we have been told a lot these couple of days [to be] independent learners. We are not supposed to be told what to [do] anymore' (sort 4). As part of making the most of the university experience, there is the desire for good library resources $(22:+1)$ : '[Good library resources allow] reading for coursework and your own joy' (sort 11).

The factor B viewpoint puts strong emphasis on being at university to work rather than socialise (23: -4$)$, and to be in the best position for a future career or postgraduate study $(29:+3)$ : 'so I can enrol for my postgraduate studies and find the job in the sector I am interested in' (sort 24). This view sees good teaching qualities as being at the heart of the university experience. It is strongly believed that tutors should teach their subjects in an interesting, enthusiastic way, while being experts in their field and good at explaining things $(39:+4 ; 5:+4 ; 1:+3 ; 28:+2)$ : 'Because it makes learning more fun and easier. Falling asleep in class doesn't teach me anything' (sort 4). Tutors are expected to be friendly and approachable $(14:+2)$, showing an interest in individual students' needs $(26:+1)$, and they should provide opportunities for discussion in class $(20:+1)$. However, it is not anticipated that students would have a lot of contact with tutors outside of class time (13: -1$)$.

The factor B viewpoint reflects feasible expectations about assessment. While the prompt marking of assignments is expected $(18:+2)$, no feedback is specifically 
anticipated on drafts (3: 0$)$, just for complete assignments $(15:+1)$. Feedback is envisaged to focus on aspects not understood by students $(33:+3)$, rather than just having the work returned with a grade (24: 0$)$, and it is also understood that this feedback might sometimes be critical and negative $(30:+3)$. A range of assessment approaches and coursework activities are welcomed to vary students' experiences (10: $+2 ; 37:+2 ; 16:-1$ ) - 'A range of tasks to vary learning and test knowledge.' (sort 3) that are spread out across the year $(9:+1)$. As it is assumed that students are at university to work, there is no concern about teaching sessions being spread out across the week with large gaps $(27:-2 ; 31:-3)$ and it is thought to be important for students to attend every lecture to ensure they keep up (34: -3$)$.

Factor C: Expecting to strike a balance between university and everyday life

Demographic summary for factor C. Factor C explained $8 \%$ of the study variance. It had six Q sorts loading on it, and these exemplars consisted of one male and five females, with ages ranging from 17 to $23(M=19.67, S D=2.34)$ years (two mature students). Five exemplars planned to work during term-time, four had English as a first language, and two were international students.

Interpretation for factor $C$. The view being put forward by the final extracted factor is the need to be practically minded and able to strike a balance between studying and everyday life while at university. There is an interest in being able to combine study with paid work during term-time $(12:+1)-$ ' $[\mathrm{I}]$ would like to earn as much money as possible while studying.' (sort 27) - and in having classes spread over as few days as possible, so other things can be fit it $(27:+2)$ : 'I prefer having teaching over as few days as possible so as I can go home [at the] weekend' (sort 12). While there is no specific 
expectation of having more time to socialise, or large breaks between classes and few early or late teaching sessions $(23: 0 ; 7:-1 ; 31: 0)$, this is clearly something of importance in this viewpoint: 'It is uncomfortable for people who live out of campus. They will waste their time waiting [for] classes ... I [am] pretty sure that it's better to have all classes one by one with short breaks' (sort 28).

As this balance is trying to be maintained, efficiencies are sought in the learning experience; tutors are expected to be good at explaining things in terms students will understand and they should be told exactly what they need to do to pass $(5:+4 ; 36:+4)$ : 'If the tutors are able to explain a subject of matter to a student or group of students in a way that they can easily accumulate the dispersed information, it will stick in the mind ... of students and be of use to them in exams or maybe even their coursework' (sort 1). While there is no desire for tutors to only cover material relating to assignments, the need to learn about everything is felt much less strongly than in the factor A and B perspectives (2: -1). Fitting with this flexible philosophy, there is a preference for all assignments to be at the end of the year (9: -1) and there is very little interest in having a range of teaching approaches, coursework activities or assessment approaches (32: -3 ; 37: 0; 10: -4): 'I don't mind if all assessment approaches are or are not the same' (sort 10). There is, however, a distinct predilection for coursework over exams $(16:+3)$, which could be due to there being more control over when coursework can be completed.

There is no particular concern about having access to university resources to help students study in this viewpoint. It is not deemed important to have study areas on campus (41: 0), good library resources (22: -1$)$, or availability of help with personal problems in an emergency (17: -2$)$. Other than expecting a grade on every piece of work that is submitted $(24:+2)$, little is expected from university tutors. There is no 
specific expectation that tutors are experts or show an individual interest in student needs $(26: 0 ; 28: 0)$. No contact is expected with tutors, either during class or outside (13: -2; 20: -2; 35: -3): 'I don't think I would use this much anyway' (sort 18). University is seen as a means to an end to get to the career that is specifically desired $(29:+3)$ : 'It is important to me to have a career and I want a higher degree to be able to work with something I love later on' (sort 18).

\section{Discussion}

The aim of the current study was to uncover shared viewpoints surrounding expectations that undergraduate students have of university at the stage they commence studying. Q Methodology was used to form in-depth profiles of expectations expressed by undergraduates. In the current sample, three shared viewpoints were articulated by participants. A key element of this research was examining the commonalities between expectations in an effort to avoid 'blanket statements' about students (Nadelson et al. 2013). It is clear from the findings that there are distinct voices reflecting different profiles of students in terms of what they want from higher education.

The factor A viewpoint (Expecting to put in the hard work and be supported by tutors) supports much of the literature on expectations of university, such as the desire for strong support from tutors, effective and prompt feedback (Brinkworth et al. 2009; Surgenor 2013), and clear directions with assessments (Balloo, Pauli, and Worrell 2015). While it could be claimed that this is indicative of the move towards students demanding universities provide a satisfying educational experience (Sander et al. 2000), the expectation to work hard in this viewpoint possibly reveals that these high expectations are actually part of an anticipated collaboration between students and tutors; if students are to work hard, then tutors should also invest as much effort to help 
them reach their potential. Therefore, a large proportion of commencing students may actually have realistic expectations of their workload, despite McInnis, James, and Hartley's (2000) findings to the contrary. For educators, this highlights the importance of higher education being a 'two-way street' in which learning is facilitated rather than imparted, so that students can be partners in this process.

The factor B standpoint (Expecting a different experience to high school) indicates a desire for an enriched experience from interested, enthusiastic and expert lecturers who are approachable and show an interest in individual student needs (Pithers and Holland 2006; Voss, Gruber, and Szmigin 2007). This standpoint is differentiated from the factor A perspective in terms of there being more interest in the experience of being at university, than the need for tutors to provide direct scaffolded support. More independence is anticipated, but tutors are expected to support students' learning by inspiring them rather than necessarily engaging in a collaborative learning experience. There are still high expectations from tutors, as has been seen in previous research, but university is not simply being positioned as a means to an end; university is an integral part of students' lives. This should provide a useful reminder to teaching staff that to some students still, their role in higher education has not been diminished to that of a service provider.

Since the factor $\mathrm{C}$ viewpoint (Expecting to strike a balance between university and everyday life) demonstrates much less concern about the university experience, and more interest in attaining an education in the most practical manner possible, this standpoint is consistent with the shift noted by Levine (1993) towards universities becoming commodities to students. This viewpoint could support Kuh's (2007) claim that some students do not enrol at university with a full appreciation of what to expect, since it could be argued that students should immerse themselves in university life in 
order to get the best possible education. However, since the focus in this viewpoint is on fitting university around other concerns, it is also possible that this is reflecting how university can be used by students in a more strategic sense to learn what is necessary to complete assessments and achieve a qualification. Rather than dismissing this perspective as students attempting to omit important aspects of their education, educators might want to consider ways of making higher education more accessible and flexible, such as timetabling classes and setting deadlines as practically as possible; accepting that students may have other priorities that might come before their education, and finding ways to accommodate this, may deal with issues around attendance, drop out and student satisfaction. Contrasting this view with those of factors A and B shows that not all students see universities this way, and in fact the majority of students may still value the experience of higher education claimed to have not been seen since the 1970s and 1980s.

While it cannot be assumed that all viewpoints of undergraduate students are being represented by these three standpoints, these findings demonstrate the potential of Q methodology to demonstrate how individual expectations coalesce to form holistic viewpoints. These perspectives therefore build on previous research as further evidence of what undergraduates anticipate when commencing university. Furthermore, this approach demonstrates that students should not be discussed in homogeneous terms when attempting to understand their expectations. At an individual statement level, statements 10, 36 and 40 (which were all related to assessment) had the largest differences between highest and lowest ranks for each factor. Since the majority of students are considered to become more focused on assessment at the expense of all other aspects of their course around deadlines (Gibbs and Dunbat-Goddet 2007), it is interesting how there is such divergence in expectations about assessment at this stage. 
Therefore, the current research appears to highlight how little students' expectations, experience and satisfaction may be related. One important limitation to the current research is that the literature still does not distinguish between expectations and aspirations, meaning that the expectations exhibited by students may actually represent socially desirable views or in fact aspirations of university (i.e. aspects that students would like to see, but not things they genuinely expect from university). Therefore, this may be an issue in the current study if expectations are only what students think they want. Future research should aim to disentangle these two concepts, possibly through contrasting what students expect from university, but do not in fact want, with aspects they actually desire from their studies.

\section{Conclusions and Recommendations}

The in-depth profiles in the current study provide educators with a useful indication of differences in expectations that exist and how they might consider dealing with any discrepancies between expectations and the actual service to be provided. It is likely that no students' experiences would wholly match up with the expectations expressed in each factor profile. This has important consequences for the NSS, since unfulfilled expectations are likely to lead to poorer student satisfaction, and this may be reflected on this survey. Therefore, the current study's findings should provide useful implications for teaching practices. Educators could try to become more aware of what students expect from their learning experience while at university; if many students expect something from university that is at odds with what can be provided, or not what the university would expect from them at that level of education, it is important to explain this to students early on in their degree. This may improve attendance, reduce likelihood of dropping out and improve overall student satisfaction (Lobo and Gurney 2014). Future research may consider extending this development of profiles to consider 
student experiences at different stages of their degrees. Longitudinal research tracking the links between expectations, experience and satisfaction would provide universities with key information on how to improve their service. This may also highlight whether the expectations held at the beginning of the degree are realistic representations of what students actually want from university. 


\section{References}

Balloo, K., R. Pauli, and M. Worrell. 2015. 'Undergraduates' Personal Circumstances, Expectations and Reasons for Attending University." Studies in Higher Education. Advance online publication. doi:10.1080/03075079.2015.1099623.

Briggs, S. 2006. "An Exploratory Study of the Factors Influencing Undergraduate Student Choice: The Case of Higher Education in Scotland." Studies in Higher Education 31 (6): 705-22. doi:10.1080/03075070601004333.

Brinkworth, R., B. McCann, C. Matthews, and K. Nordström. 2009. "First Year Expectations and Experiences: Student and Teacher Perspectives.” Higher Education 58 (2): 157-73. doi:10.1007/s10734-008-9188-3.

Brown, S. R. 1980. Political Subjectivity: Applications of Q Methodology in Political Science. New Haven, CT: Yale University Press.

Crisp, G. T., E. J. Palmer, D. A. Turnbull, T. Nettelbeck, L. Ward, A. LeCouteur, A. Sarris, P. Strelan, and L. Schneider. 2009. "First Year Student Expectations: Results from a University-wide Student Survey.” Journal of University Teaching \& Learning Practice 6 (1): 10-26.

Gibbs, G. R., and H. Dunbat-Goddet. 2007. "The Effects of Programme Assessment Environments on Student Learning.” Accessed December 202016. https://www.heacademy.ac.uk/system/files/gibbs_0506.pdf.

Hackert, C. FlashQ (http://www.hackert.biz/flashq) (Version 1.0). Flash. 2007.

Kuh, G. D. 2007. "What Student Engagement Data Tell Us About College Readiness.” Peer Review 9 (1): 4-8.

Levine, A. 1993. "Editorial: Student Expectations of College.” Change: The Magazine of Higher Learning 25 (5): 4. doi:10.1080/00091383.1993.9939896.

Lobo, A., and L. Gurney. 2014. "What Did They Expect? Exploring a Link Between Students' Expectations, Attendance and Attrition on English Language 
Enhancement Courses.” Journal of Further and Higher Education 38 (5): 730-54. doi:10.1080/0309877X.2013.817002.

McInnis, C., R. James, and R. Hartley. 2000. "Trends in the First Year Experience in Australian Universities.” Accessed July 5 2016. http://melbournecshe.unimelb.edu.au/research/experience/trends-in-the-first-year-experience.

Nadelson, L. S., C. Semmelroth, G. Martinez, M. Featherstone, C. A. Fuhriman, and A. Sell. 2013. "Why Did They Come Here? -The Influences and Expectations of First-year Students' College Experience.” Higher Education Studies 3 (1): 50-62. doi:10.5539/hes.v3n1p50.

The National Student Survey. 2016. “About the NSS.” The National Student Survey. Accessed July 5 2016. http://www.thestudentsurvey.com/about.php.

Pithers, R, and A. Holland. 2006. "Student Expectations and the Effect of Experience." Paper presented at the Australian Association for Research in Education annual conference, Adelaide, Australia, November 26-30.

Richardson, J. T. E., J. B. Slater, and J. Wilson. 2007. “The National Student Survey: Development, Findings and Implications.” Studies in Higher Education 32 (5): 557-80. doi:10.1080/03075070701573757.

Sander, P., K. Stevenson, M. King, and D. Coates. 2000. “University Students' Expectations of Teaching." Studies in Higher Education 25 (3): 309-23. doi:10.1080/03075070050193433.

Schmolck, P. PQMethod (http://schmolck.userweb.mwn.de/qmethod) (Version 2.33). DOS. 2002.

Stainton Rogers, R. 1995. “Q Methodology.” In Rethinking Methods in Psychology, edited by J. A. Smith, R. Harre, and I. Van Longenhove, 178-93. London: Sage. Surgenor, P. W. G. 2013. 'Measuring up: Comparing First Year Students' and Tutors' 
Expectations of Assessment." Assessment \& Evaluation in Higher Education 38 (3): 288-302. doi:10.1080/02602938.2011.630976.

Voss, R., T. Gruber, and I. Szmigin. 2007. "Service Quality in Higher Education: The Role of Student Expectations.” Journal of Business Research 60 (9): 949-59. doi:10.1016/j.jbusres.2007.01.020.

Watts, S., and P. H. D. Stenner. 2005. "Doing Q Methodology: Theory, Method and Interpretation." Qualitative Research in Psychology 2 (1): 67-91. doi:10.1191/1478088705qp022oa.

Watts, S., and P. H. D. Stenner. 2012. Doing Q Methodological Research: Theory, Method and Interpretation. London: Sage. 
Table 1. Demographics and personal circumstances of students in the sample

$n \quad \%$

Gender

Male

$2 \quad 7.1$

Female

$26 \quad 92.9$

Age groups ${ }^{a}$

Under 21

$22 \quad 78.6$

Mature student

$6 \quad 21.4$

Ethnicity $^{b}$

White

Black or Black British

Asian or Asian British

$8 \quad 28.6$

Mixed

$\begin{array}{ll}3 & 10.7\end{array}$

Other

$3 \quad 10.7$

Carer responsibilities

Carer

$1 \quad 3.6$

Non-carer

$27 \quad 96.4$

Application route

$\mathrm{UCAS}^{\mathrm{c}}$

$24 \quad 85.7$

Direct application

$1 \quad 3.6$

Clearing $^{\mathrm{d}}$

$\begin{array}{ll}3 & 10.7\end{array}$

Working during term-time

Yes

$19 \quad 67.9$

No

$9 \quad 32.1$

Fee status ${ }^{\mathrm{e}}$ 


\begin{tabular}{|c|c|c|}
\hline Home & 23 & 82.1 \\
\hline International & 5 & 17.9 \\
\hline \multicolumn{3}{|l|}{ Language } \\
\hline English is first (or equal first) language (EFL) & 21 & 75.0 \\
\hline English is second (or more) language (ESL) & 7 & 25.0 \\
\hline \multicolumn{3}{|c|}{$\begin{array}{l}\text { a The Universities and Colleges Admissions Service (UCAS) define a mature student as } \\
\text { anyone aged } 21 \text { or over at the beginning of their degree. } \\
\text { b Ethnic categories are based on those adopted by the England and Wales Census and } \\
\text { therefore generally used in the UK. } \\
\text { c UCAS is the usual route that undergraduates take when applying for a university place } \\
\text { in the UK. } \\
\text { d If students do not receive a place at university via UCAS, they may have an } \\
\text { opportunity to apply for another programme or a different university via a process } \\
\text { called clearing after they have received their grades. Often, places offered via clearing } \\
\text { have a lower entry grade tariff than places taken up earlier via the UCAS route. } \\
{ }^{\mathrm{e}} \text { Students from the UK/EU (home students) pay a tuition fee at UK universities that is } \\
\text { lower than what international students (nationals of countries outside the EU) pay. }\end{array}$} \\
\hline
\end{tabular}


Table 2. Varimax rotated centroid factor analysis loadings of Q sorts

\begin{tabular}{|c|c|c|c|c|}
\hline & \multicolumn{3}{|c|}{ Factor } & \multirow[b]{2}{*}{$h^{2}$} \\
\hline & $\mathrm{A}$ & B & $\mathrm{C}$ & \\
\hline Sort 1 & .06 & .12 & $.31 * \mathrm{a}$ & .12 \\
\hline Sort $2^{b}$ & .21 & $.27^{\mathrm{a}}$ & .07 & .12 \\
\hline Sort 3 & $.36^{*}$ & $.58 * * * a$ & -.005 & .47 \\
\hline Sort 4 & .06 & $.74 * * * \mathrm{a}$ & -.12 & .57 \\
\hline Sort 5 & $.58 * * * \mathrm{a}$ & .12 & .06 & .35 \\
\hline Sort 6 & $.39 * \mathrm{a}$ & -.06 & .21 & .20 \\
\hline Sort 7 & $.86 * * * a$ & .25 & .13 & .82 \\
\hline Sort $8^{\mathrm{b}}$ & $.37 *$ & $.39 *$ & $.35^{*}$ & .41 \\
\hline Sort 9 & $.48 * * a$ & .23 & -.04 & .28 \\
\hline Sort 10 & .29 & $.64 * * * a$ & $.45^{* *}$ & .70 \\
\hline Sort 11 & .14 & $.56 * * * a$ & .22 & .38 \\
\hline Sort 12 & .08 & .03 & $.46^{* * \mathrm{a}}$ & .22 \\
\hline Sort 13 & $.57 * * * \mathrm{a}$ & $.53 * * *$ & -.12 & .62 \\
\hline Sort 14 & $.33 *$ & .19 & $.44 * * \mathrm{a}$ & .34 \\
\hline Sort 15 & $.50 * * a$ & .18 & $.36^{*}$ & .42 \\
\hline Sort 16 & -.004 & $.42 * * a$ & $.32 *$ & .28 \\
\hline Sort 17 & $.64 * * * a$ & $.43 * *$ & .30 & .69 \\
\hline Sort 18 & $.32 *$ & .18 & $.50 * * \mathrm{a}$ & .39 \\
\hline Sort 19 & $.44 * * a$ & .21 & $.37 *$ & .37 \\
\hline Sort 20 & $.60 * * * \mathrm{a}$ & .06 & .16 & .39 \\
\hline Sort 21 & $.64 * * * \mathrm{a}$ & $.40 *$ & .30 & .66 \\
\hline Sort 22 & $.44 * * \mathrm{a}$ & .19 & .25 & .29 \\
\hline
\end{tabular}




\begin{tabular}{lcccc}
\hline Sort 23 & .26 & $.47 * * \mathrm{a}$ & .18 & .32 \\
Sort 24 & $.47 * *$ & $.53 * * * \mathrm{a}$ & .19 & .53 \\
Sort 25 & .02 & $.56^{* * * \mathrm{a}}$ & .12 & .33 \\
Sort 26 & $.34 *$ & $.82 * * * \mathrm{a}$ & .10 & .80 \\
Sort 27 & .03 & -.05 & $.37 * \mathrm{a}$ & .14 \\
Sort 28 & .08 & .08 & $.40 * \mathrm{a}$ & .17 \\
Eigenvalue & 4.76 & 4.48 & 2.24 & \\
Variance $\%$ & 17 & 16 & 8 & \\
\hline
\end{tabular}

Note. $N=28$.

${ }^{a}$ Square of factor loading exceeds half of its variance/communality $\left(h^{2}\right)$.

${ }^{\mathrm{b}} \mathrm{Q}$ sort has not met the factor exemplar criteria.

$* p<.05$.

$* * p<.01$.

$* * * p<.001$. 
Table 3. Factor array ranks

Factors

\#

Statement

A $\quad$ B $\quad$ C

1 Tutors being enthusiastic about what they teach

$+1 \quad+3 \quad \underline{0}$

2 Only being taught material that I need to know to

$\underline{-3} \quad-2 \quad-1$
complete my coursework and exams

3 Receiving feedback on DRAFTS of my assignments

4 Finding studying at university to be much the same as studying at high school/sixth form/college

5 Tutors being good at explaining things in terms that I $\underline{0} \quad+4 \quad+4$ will understand

6 Tutors showing warmth and humour $\underline{0} \quad \underline{0} \quad+1$

7 Having few early and/or late teaching sessions $\underline{-4} \quad-3 \quad-1$

8 Having a good availability of help with academic $\quad \underline{+1} \quad \underline{+1} \quad+3$ writing

9 Assessments being evenly spaced throughout the year, $\quad+1 \quad+1 \quad \underline{-1}$ rather than all being due at the end of the year

10 Having a range of assessment approaches (e.g. exams, $\quad \begin{array}{llll}0 & +2 & -4\end{array}$ coursework, presentations, etc.)

11 Support from the university with non-academic

$\underline{-2} \quad \underline{-2} \quad \underline{-2}$ activities and social interaction

12 Being able to combine study with paid work $\underline{-3} \quad-1 \quad+1$

13 Having a lot of contact with tutors outside of the $-1 \quad-1 \quad \underline{-2}$ classroom

14 Tutors being friendly and approachable at all times

$\begin{array}{lll}0 & +2 & +1\end{array}$


15 Receiving feedback on ALL of my submitted

$+4 \quad \underline{+1}+3$ assignments

16 Having more coursework than exams

$\underline{-1} \quad \underline{-1} \quad+3$

17 Having a good availability of help with personal

$-1 \quad-1 \quad \underline{-2}$ problems in an emergency

18 Getting assignments marked and returned promptly

$+2 \quad+2 \quad \underline{+1}$

19 Having the majority of study time occurring during $\quad \underline{-2} \quad \underline{-2} \quad \underline{-2}$ timetabled classes rather than my own time

20 Tutors providing opportunities for questions and/or $\quad \begin{array}{llll}\mathbf{+ 1} & \mathbf{+ 1} & \underline{-2}\end{array}$ classroom discussion

21 Having an opportunity to work with other students

$\underline{-3} \quad 0 \quad-1$
during class time

22 Having a good availability of library resources

$\underline{-1}+\mathbf{1} \quad \underline{-1}$

23 Getting to spend more than 15 hours per week relaxing $\underline{-4} \quad \underline{-4} \quad \mathbf{0}$ and socialising

24 Receiving a grade on every piece of work I submit $+2 \quad \underline{0} \quad+2$

25 Not having to study for more than 15 hours per week $\quad \underline{-3} \quad \underline{-3} \quad \underline{-3}$

26 Tutors showing an interest in individual students' needs $\quad \underline{0} \quad \begin{array}{lll}\mathbf{+ 1} & \underline{0}\end{array}$

27 Teaching sessions being spread over as few days per $\quad \underline{-2} \quad \underline{-2} \quad+2$ week as possible

28 Tutors being experts in the subject matter they are $\quad+1 \quad+2 \quad \underline{0}$ teaching

29 Being in the position to complete further study with a $\quad \underline{+2} \quad+\mathbf{3} \quad+\mathbf{+ 3}$ higher degree after graduating 
30 Tutors providing critical and sometimes negative

$+3 \quad+3 \quad \underline{-1}$
feedback

31 Having no large breaks/gaps between classes each day $\quad \begin{array}{llll}-1 & \underline{-3} & \mathbf{0}\end{array}$ in my timetable

32 Having a range of different teaching approaches (e.g. $\quad+1 \quad 0 \quad 0 \quad \underline{-3}$ formal lectures, tutorials, group work, etc.) be used

33 Getting feedback on assignments that is more focused $\quad \begin{array}{lll}\mathbf{4} & +3 & +2\end{array}$ on clarifying things I did not understand, rather than justifying the grade

34 Being able to keep up with my studies without having $\quad \begin{array}{llll}-2 & \underline{-3} & \underline{-3}\end{array}$ to attend every timetabled lecture

35 Having 'ready' access to tutors outside of face-to-face $\quad \begin{array}{llll}\mathbf{0} & -1 & \underline{-3}\end{array}$ teaching

36 Being explicitly told by tutors what is required to pass $\quad \begin{array}{lllll}\mathbf{+ 1} & \underline{-1} & \mathbf{+ 4}\end{array}$ an assignment

37 Being set coursework involving a range of activities $\quad \begin{array}{llll}\mathbf{+ 2} & \mathbf{+ 2} & \underline{0}\end{array}$ (e.g. essays, laboratory work, research projects, poster/oral presentations, course journals, computer exercises, problems/exercises, etc.)

38 Having a good availability of help with maths/statistics $\quad+\mathbf{3} \quad \underline{0} \quad+1$

39 Tutors teaching their subject in an interesting way, even $\begin{array}{llll}\underline{0} & \mathbf{+ 4} & +2\end{array}$ when it is not an interesting subject

40 Tutors clearly directing me to all of the reading I need $\quad+3 \quad \underline{-2} \quad+2$ to do to complete assignments

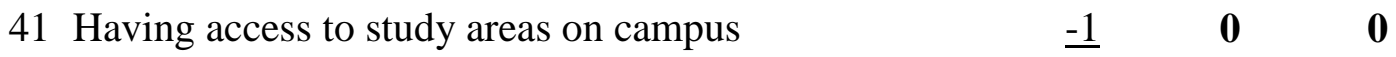


Note. Rankings in bold signify the highest rank (most important) given for that particular statement, whereas underlined rankings signify the lowest rank (most unimportant) for that statement. 
MOST UNIMPORTANT TO ME

NEUTRAL MOST IMPORTANT TO ME

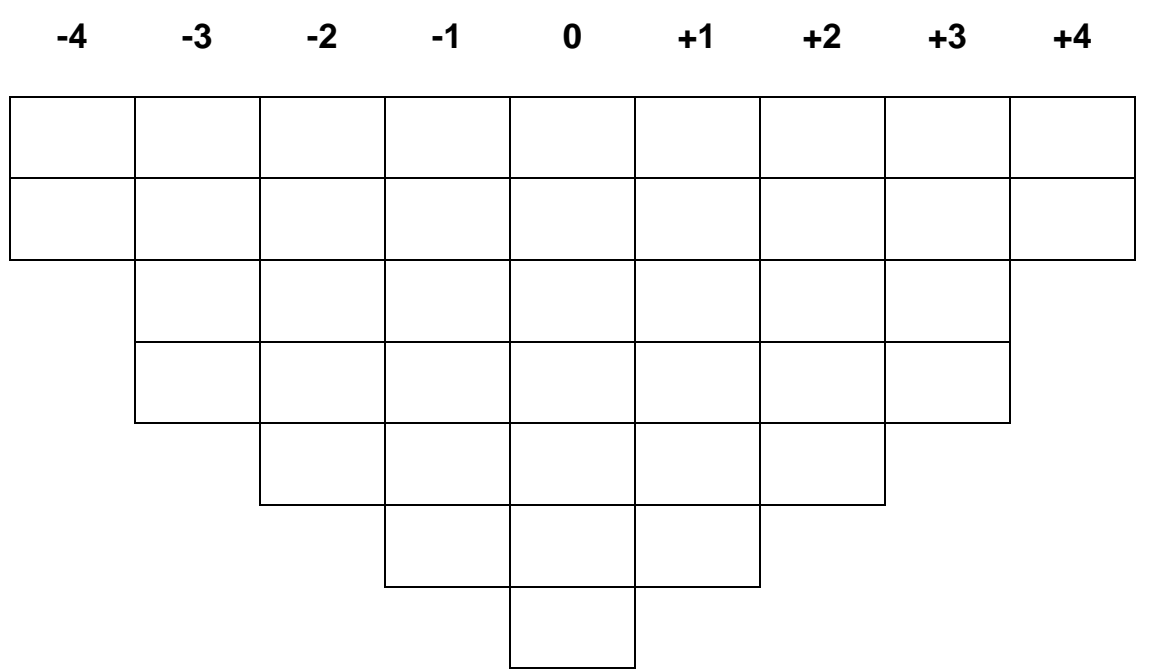

Figure 1. Q sorting grid 